\title{
Traditional Medicine and Primary Health Care in Sri Lanka: Policy, Perceptions, and Practice
}

\author{
Margaret Jones \\ University of York \\ margaret.jones@york.ac.uk \\ Chandani Liyanage \\ University of Colombo \\ chandaniliyanage@soc.cmb.ac.lk
}

\begin{abstract}
Primary Health Care was launched on the international stage by the World Health Organization's Alma Ata Declaration of 1978. This paper begins by unpicking the concept of primary health care as it evolved after Alma Ata and then explores its implementation in Sri Lanka and the extent to which Ayurveda (a blanket term for the traditional medical systems of Sri Lanka) has been integrated into the government health care system. The substantive part of the paper analyzes the responses of the traditional practitioners who were invited to explore the issues outlined above in a series of interviews. Part historical and part sociological, this discussion of the similarities and the divergences between the approaches of biomedicine and traditional medicine in Sri Lanka from the perspective of the Ayurvedic practitioner exposes the tenuous and disconnected part they play within the biomedical health care system at the practical level.
\end{abstract}

* We would like to thank the Wellcome Trust for its generous support in the funding of this research. We are grateful to an anonymous reviewer for comments on an earlier draft and to Monica Saavedra for her insightful suggestions. We are also very grateful to Chathuri Gunathilaka, our research assistant, for her most valuable contribution in conducting and transcribing the interviews with our sample practitioners.

(C) MARGARET JONES AND CHANDANI LIYANAGE, 2018 | DOI 10.1163/22879811-12340029

This is an open access article distributed under the terms of the prevailing CC-BY-NC-ND license at the time of publication. 


\section{Keywords}

Ayurveda - integration - primary health care - Sri Lanka - traditional medicine Western medicine

\section{Introduction}

The Sri Lankan Government's Health Master Plan of 2007-2016, Healthy and Shining Island in the 21st Century, set out to plan for the health challenges facing the people of Sri Lanka as the new century progressed. These challenges included "changing demographic and disease patterns, limited resources, increased demand and expectations by the public and the need for equity" (Ministry of Healthcare and Nutrition 2007 , iii). ${ }^{1}$ Sri Lanka, in common with other low- and middle-income countries faces a double disease burden of communicable and noncommunicable diseases, with accompanying rising medical and welfare costs (Lewis and MacPherson, 2013). The 2007 health planning blueprint was thus the government's response to this health transition, or as it might be termed, this "health crisis" (Ministry of Healthcare and Nutrition $2007,19)$. It planned for an integrated approach with three functional arms: preventive, curative, and welfare. All three of these arms were deemed to be interdependent; furthermore, the blueprint acknowledged that the branches of traditional medicine, that is, Ayurveda, Unani, and Siddha, "collectively constitute an integral part of the health sector," and that the practitioners of traditional medicine have an essential role in the provision of universal health services (Ministry of Healthcare and Nutrition 2007, 7). ${ }^{2}$ Ayurveda with its holistic approach to health was deemed particularly apposite for the delivery of preventive medicine. ${ }^{3}$

The commitment to using traditional medicine alongside Western government health services is not innovative; it has a long history in Sri Lanka at least at the level of stated government policy. How far this has been put into practical effect is another question. This paper, through the means of a purposive

1 Sri Lanka was the British colony of Ceylon until gaining independence in 1948. In 1972 it became the republic of Sri Lanka, while remaining within the British Commonwealth.

2 Ayurveda is used as a general term for all traditional medical systems in Sri Lanka, and this nomenclature will be followed here.

3 The "life course approach" entails a preventive strategy "based on tackling the risk factors from the foetal stage to old age" (Ministry of Healthcare and Nutrition 2007, 15). 
qualitative survey of a sample of traditional medical practitioners (TMP) in and around the Colombo area in April 2014, aims to explore how traditional practitioners themselves perceived their role in the delivery of primary health care and their part in the formal medical system at the time of their interviews. Primary health care with its emphasis on prevention is considered the most effective means of dealing with the double disease burden facing many low- and middle-income countries that have limited resources for health care services. This study begins by exploring definitions of primary health care; how it is delivered in Sri Lanka; and how traditional medicine fits into Sri Lanka's overall health delivery system in the light of proposed government policy. The second part of the paper analyzes the responses of the sample TMPs within this context.

\section{Primary Health Care: Definitions}

The concept of primary health care has been subject to shifting and at times competing interpretations. The term as originally used in the nineteenth and twentieth centuries applied to the provision of services for basic preventive and curative care. It has since acquired other attributes at the international level. Does it also encompass agrarian reform, nutrition, sanitation, pure water supply, education, and anti-poverty strategies? Can it be a mechanism to empower people and communities for broad developmental purposes? Such questions about the meaning and functions of primary health care entered the global stage at the World Health Organization (wHo) Alma Ata Conference of 1978. They grew out of the growing acceptance in the 1970 s of the tremendous disparities in the provision of health care between and within countries. For Halfdan Mahler $(1978,109)$, wHO's director general (1973-1988), "the necessity to proceed with implementing primary health care is part of a wider necessity to seek social justice." The example of China's barefoot doctors and socialist medicine in the USSR determined the location for this remarkable rare example of international agreement, and the failure of the wHo's malaria eradication program provided the trigger. The meeting in Alma-Ata, a city in the former Soviet Union (now in Kazakhstan), in September 1978 brought together leaders from east, west, north, and south: representatives from 134 countries and from the UN agencies, which traditionally did not have a good record of cooperative engagement. It was billed as a primary health care ( $\mathrm{PHC}$ ) revolution but in reality it aimed to be much more than just an improvement in primary health care. It advocated a "comprehensive philosophy of development" 
and represented a "shift in thinking that saw health not merely as a result of biomedical interventions but also an outcome of social determinants" (Lawn et al. 2008, 919).

The resulting Alma-Ata declaration reaffirmed the wHo's definition of health, asserted that the promotion of health was a government responsibility, that inequalities in health status were unacceptable, and that health was a fundamental human right (wHO 1978a). What was also challenging about the Alma-Ata declaration was the means it proposed to achieve these objectives. Primary health care, according to the declaration, should be based on practical, scientific and socially acceptable methods and technologies, and it should be universally accessible to individuals and families in the community by means acceptable to them, through their full participation, and at a cost that the community and the country could afford. Furthermore, it should form an integral part of the health system, the first level of contact between the individual and the community, bringing health care as close as possible to where people lived and worked; and significantly it should be the nucleus of the overall social and economic development of the community (wHO 1978a). It depended on an intersectoral approach that encompassed food supply and nutrition, safe water and sanitation, health education, maternal and child health including family planning, immunization, access to treatment, prevention and control of disease, and the availability of essential drugs (wHO 1978a). ${ }^{4}$ Moreover, the need to ensure that health services were acceptable to communities entailed the inclusion of traditional medicine within this package. There were sound economic arguments for this inclusion; to provide access to Western medicine for entire populations in resource-poor countries was not a viable aim. Western medicine was expensive and Western medical practitioners did not want to serve in rural areas. The use of traditional medicine addressed both these problems; it was cheaper and it was accessible even in the more remote areas. Hence, in 1978 the WHO argued for its promotion and development on the grounds that it was "one of the surest means to achieve total health coverage of the world population, using acceptable, safe, and economically feasible methods, by the year 2000" (wHO 1978b).

However, in the climate of the 1980s, when global development policy was dominated by neoliberal macroeconomics with its emphasis on cuts in public

4 This intersectoral and community approach was not, however, new. It harked back, as Mahler pointed out in 1978, to the 1937 League of Nations Conference on Rural Hygiene in Bandoeng, Java, which had recommended the need for "reconstruction that entailed the collaboration of the population, sanitation and sanitary engineering, [and] nutrition," as well as "health and medical services" (Mahler 1978, 107). 
spending and the reduction of budget deficits, the ambitions of Alma-Ata were curtailed and primary health care came to mean selective programs such UNICEF's "child survival" program and the GOBI strategy of growth monitoring, oral rehydration, breast feeding, and immunization. ${ }^{5}$ By the 1990 s progress toward the Alma-Ata goal of "Health for All by 2000 " had stalled. The next set of objectives, the Millennium Development Goals (set at the G8 summit in 2000), had to contend with new and major health threats like AIDS, multi-drug resistant tuberculosis, and the rise of chronic diseases in both north and south that gave the concept of comprehensive primary health care (now termed universal health coverage) renewed vigor. The present wHo Director, Margaret Chan $(2008,865)$ has reaffirmed a commitment to the principles of Alma-Ata and stated that "Primary health care increasingly looks like the smart way to get health development back on track" (see also wHO 2008b). Similarly, the 2008 wHo Congress on Traditional Medicine issued the Beijing Declaration that reiterated the vital role that traditional medicine should play in the delivery of universal health care (WHO 2008a). The traditional medical systems remain at the forefront of the strategy to deal with the present health challenges at both the national and international level. Furthermore, it has been argued that Ayurveda in Sri Lanka, despite its uncertain and varying official and practical presence, has had a positive influence on health norms because it places great value on a healthy lifestyle and eschews a fatalistic attitude to illness, with the result that Sri Lankans' health-seeking behavior predisposes them to accessing medical aid in whatever form (Pieris 1999; Caldwell et al. 1989). Thus traditional medicine clearly does and could play a significant role in the health-seeking behavior of Sri Lankans.

\section{Primary Health Care in Sri Lanka: The Context}

Sri Lanka has long been recognized in international health circles as providing "good health at low cost" based on an effective primary health care system. ${ }^{6}$ When it gained independence in 1948 the nation had an "embryo welfare state" based on free education, food subsidies and, crucially, free health

5 There was an extensive debate on the implications of selective primary health care (SPHC) and comprehensive primary health care ( $\mathrm{PHC}$ ) within the pages of Social Science and Medicine. See, for example, the articles in vol. 26, no. 9 (1988) and Cueto 2004.

6 A term from the iconic report of the Rockefeller Foundation in 1985 (Halstead, Walsh, and Warren 1985) that highlighted the experience of Sri Lanka, China, Costa Rica, and Kerala State, India (all low-income countries), in delivering good health indicators. 
TABLE 1 Selected human development indicators for Sri Lanka, India, the United Kingdom (UK), and the United States (US) for the year 2011

\begin{tabular}{|c|c|c|c|c|}
\hline Indicator & Sri Lanka & India & UK & Us \\
\hline Life expectancy at birth & 74 & 66 & 81 & 79 \\
\hline Infant mortality rate per 1,000 live births & 8 & 44 & 4 & 6 \\
\hline $\begin{array}{l}\text { Maternal mortality rate per 100,0oo live } \\
\text { births }\end{array}$ & 35 & 200 & 12 & 21 \\
\hline $\begin{array}{l}\text { Improved sanitation facilities (\% of the } \\
\text { population with access) }\end{array}$ & 91 & 35 & 100 & 100 \\
\hline $\begin{array}{l}\text { Immunization, DPT ( } \% \text { of children ages } \\
12-23 \text { months }\end{array}$ & 99 & 72 & 97 & 95 \\
\hline Health expenditure per capita US\$ & 59 & 97 & 3,609 & 8,608 \\
\hline GDP per capita US\$ & 2,923 & 1,489 & 39,093 & $5^{1,749}$ \\
\hline
\end{tabular}

SOURCE: WWW.WORLDBANK.ORG/INDICATORS (ACCESSED APRIL 4, 2014).

care; it also had a government that accepted the wHo definition of health as a fundamental human right (Silva 1997, xxxii). Infant and maternal mortality rates and life expectancy maintained a steady improvement in the second half of the twentieth century despite economic depression and internal conflict. Table 1 illustrates how Sri Lanka compared in certain key indicators with its northern neighbor India, the United Kingdom and the United States in the first decade of the twenty-first century and effectively demonstrates that Sri Lanka's reputation is well earned. It shows that Sri Lanka has better health indicators than its northern neighbor, India; and more remarkably, it has comparable indicators with the high-income countries of the United Kingdom and the United States. Notably, these achievements are obtained in Sri Lanka at a much lower level of health expenditure per capita and overall GDP than in the two rich nations.

This success stems from a variety of factors. From 1948 to 1977 Sri Lanka operated as a social welfare state providing free education, health care, and subsidized food. With the advent of neoliberalism, state welfare was limited and targeted at the most needy, but free health care continued to be a government priority. The development of the extensive primary health care structure can be traced back to the colonial period, when the indigenous medical profession was instrumental in pushing for the growth of Western medical services; the new nation in 1948 had both an extensive network of curative institutions 
and significantly a preventive health care system based around the health unit (Hewa 1995; Jones 2004; 2009). ${ }^{7}$ The health unit delivered the services that are the foundation of primary health care at the community level: maternal and child welfare, immunizations, sanitary inspections, health education, the prevention of communicable diseases, and the training of public health workers. By the time of Alma Ata there were ninety-eight such units under the direction of a medical officer of health $(\mathrm{MOH})$ assisted by a team of field health workers (public health nurses, midwives, and inspectors), and they served as a model for other low-income countries (Simeonov 1975, 83). Alma-Ata served to reinforce Sri Lanka's primary health care structure with the establishment of a National Health Council (1980), and Family Health and Education Bureaus at the top of the health care pyramidal infrastructure. At the bottom of the pyramid were the village development committees and village health workers. The objective was to ensure equity in access to health services and to lessen health disparities within the island (Fernando and Cooray 1991). The contemporary equivalent of the health units system are the Divisional Directorates of Health Services established in 1992 (by 1997 they numbered 238) under a Divisional Director (DDHS) who has a defined geographical area of responsibility and a defined population for both curative and preventive care (the latter incorporating the preventive activities of the health units) (Fernando 2000, 15-16).

However, government health expenditure was and remains disproportionately focused on the curative sector. In 1975 Simeonov $(1975,173)$ estimated that for every twelve cents spent on the prevention of diseases and the promotion of health, one rupee was spent on treatment. Twenty years later, in 1994, Dulitha Fernando $(2000,17)$ estimated that the percentage difference was 61.9 percent on curative care, with 24.7 percent on general administration and 12.0 percent on community health services. Furthermore, the Ministry of Health's own report in 2003 suggested that the proportion of total expenditure on preventive and public health expenditure had declined from 11 percent in 1990 to 6 percent by 1999 (Ministry of Health 2003, ch. 2, par. 2.8.3, 20).

Alongside the government services there is now a growing private sector particularly for ambulatory or outpatient care. According to government statistics, there were an estimated 45 million outpatient visits of all kinds in 2007; $5^{0}$ percent of these were serviced by the private sector, 34 percent by government doctors, 11 percent by private general practitioners, and 5 percent of this total by traditional practitioners (Ministry of Health 2017). Given that the take up of services provided by traditional medicine is less easily quantifiable than

7 The first health unit was established in 1926 at Kalutara in collaboration with the Rockefeller Foundation. 
for the services provided by Western medicine, official statistics no doubt underestimate its importance in personal health. ${ }^{8}$

\section{Ayurveda and Primary Health Care}

Under colonial rule the traditional medical systems declined in status but not in availability or use, and they were an integral aspect of the cultural revival and political nationalism of the first decades of the twentieth century. In the struggle to survive against the onslaught from biomedicine they were forced to professionalize and institutionalize. They were recognized and subsidized by the government from the 1930s onward and thus viewed as part of the official medical landscape (Jones 2004, 83-104). However, Simeonov (1975, 95) argued in 1975 that although the traditional medical sector constituted "a system for providing services spread over the whole country," traditional practitioners did not "participate in either family health or in the control of communicable diseases" in a formal sense. ${ }^{9}$ Although Ayurveda was still used extensively by the population and the government financed a system of Ayurveda hospitals and clinics, the hostile attitude of the Western medical establishment precluded its involvement in public health (Arseculeratne 2002; Jones 2008). However, in the aftermath of the Alma-Ata Declaration and in line with one of its tenets, it was proposed that traditional practitioners in Sri Lanka should play a part in health promotion and disease prevention and give "collaborative support to community care" (Fernando and Cooray 1991, 238).

Today the official contribution of the traditional sector to community health comes under the Ministry of Health, Nutrition, and Indigenous Medicine and its community healthcare program for the prevention of disease. This program began in 2004 with a pilot project in the Anuradhapura district and then spread throughout the entire island. It focuses on nutrition, mental health, the control of contagious and noncontagious diseases, renal problems, and diabetes. Community health promotion medical officers (CMOs) trained in traditional medicine are responsible for its implementation (Ministry of Health n.d.). Traditional medicine thus has a recognized role in the supply and stewardship of health care as well as in the pursuit of personal health. In both of those roles it is supposedly integrated into the delivery of primary health care.

8 "Western medicine" is the term used for allopathic/cosmopolitan/biomedicine in Sri Lanka, and it will be used in this sense throughout this paper.

9 For an exploration of how traditional medical systems could contribute to primary health care, see Young 1983 . 
The purpose of our survey was therefore to uncover as far as possible the reality behind both international and national rhetoric on the role of traditional medicine in primary health care.

\section{The Specificities of Ayurveda in Sri Lanka}

Ayurveda is the official term used in Sri Lanka to denote collectively all the traditional medical systems. It encompasses Ayurveda, the predominant system which came to the island from India with Buddhism 2,500 years ago, as well as Siddha, Unani, and Desiya Chikithsa, the latter being the earliest system of medicine existing in Sri Lanka before the advent of Ayurveda. ${ }^{10}$ The term "traditional medicine" thus largely overlaps with the term "Ayurveda." According to the Ayurveda Act, No. 31 of 1961, the Ayurveda medical system includes all of the above medical systems, as they are deemed integrated with Ayurveda to a large extent. However, the Ayurveda that emerged in Sri Lanka from the middle decades of the twentieth century is a complex mixture of the island's indigenous medical practices, Ayurveda, and elements of Western medicine. As noted previously, from the 1920 s onward Ayurveda was forced to establish a professional identity in order to compete with the formally organized and government-funded Western medicine. This entailed presenting Ayurveda, as Dagmar Wujastyk and Frederick Smith $(2008,7)$ have argued, "at political and ideological levels, as a uniform medical system" with all the attributes of the Western medical system. The "biomedicalization" of Ayurveda has provoked much debate within Sri Lanka on the nature and practice of the Ayurveda that emerged from this process. The establishment of training institutions (where Western medicine was also taught), certification, registration, and canons of knowledge has led to claims that what has resulted is a "hybrid" between Western and traditional medicine, as opposed to the pure form that had previously been practiced when knowledge was passed down within families. ${ }^{11}$ As Madhulika Banerjee $(2008,201-202)$ has argued, it was also accompanied by the "pharmaceutilzation" of Ayurveda, whereby its medicines "become indistinguishable from any other pharmaceuticals" thereby eroding its "capacity as an "alternate system." These adaptations make it difficult to identify any of the different practices within Sri Lankan traditional medicine as discrete systems (Wanninayaka 1982). Sri Lankans very often use the term "Ayurveda"

\footnotetext{
10 For an exploration of definitions of medical systems, see Dunn 1976; Young 1983.

11 Such views were aired extensively in the Legislature from the start of this process in the 1920s. See Jones 2004, 99-102.
} 
not specifically to indicate only the Ayurveda medical system but equally to indicate all the traditional medical systems, some of which in practice also use the tools of Western medicine. For this reason we have deliberately chosen our sample of practitioners to represent the full spectrum of TMPs in order to highlight their diverse views, practices, and experiences.

\section{The Characteristics of the Sample of Traditional Practitioners}

The first group of practitioners are from the Desiya Chikithsa tradition. Although it is integrated with Ayurveda and its practitioners can be registered, in practice Desiya Chikithsa can be quite different from Ayurveda. It is based mainly on a knowledge system that is gained through experience rather than deriving from philosophical concepts or written texts. Its customs and value systems are handed down from one generation to another and are inherited within a family tradition. These practitioners have no formally recognized qualifications, unlike the other TMPs, who have followed a recognized course of training. The service provided by traditional practitioners who belong to Desiya Chikithsa is based on their individual skills and limited to private practice. Usually, they have their own dispensary located within the residence of the practitioner or at least close by in their community. Desiya Chikithsa is officially recognized as one of the traditional medical systems in Sri Lanka under the 1961 Ayurveda Act, but it is not incorporated in any way within the government health care delivery system (Department of Ayurveda n.d.).

Diploma holders (some with a background also in Desiya Chikithsa) straddle both the informal and formal sectors, as nearly $5^{\circ}$ percent of them have been integrated within the government indigenous health care delivery system, working in government-subsidized Ayurvedic hospitals and clinics, with the remainder deliver their services on an individual basis. Compared with the above two categories, more than go percent of degree holders, the third group, have been integrated. Degree holders have a Bachelor of Ayurveda Medicine and Surgery that includes in-depth knowledge of Ayurveda and a basic knowledge of Western medicine (WM), as it is included in the curriculum of the Ayurveda degree program. Each category of traditional practitioners has specific characteristics while still sharing many common features in their day-to-day practice. Accordingly, of the thirty traditional practitioners (TMPs) selected, ten were chosen from each category, all of whom have been registered under the Council of Indigenous Medicine in Sri Lanka. The study was located within the Colombo and Kalutara Districts mainly on the basis of accessibility criteria. The TMPs' exposure to and their perceptions of PHC and the extent to which they consider they are involved in its provision may differ 
TABLE 2 Distribution of practitioners by training and gender

\begin{tabular}{lccc}
\hline Category of Practitioner & Male & Female & Total \\
\hline Desiya Chikithsa & 9 & 1 & 10 \\
Ayurveda Diploma Holders & 3 & 7 & 10 \\
Ayurveda Degree Holders & 1 & 9 & 10 \\
Total & $\mathbf{1 3}$ & $\mathbf{1 7}$ & $\mathbf{3 0}$ \\
\hline
\end{tabular}

based on the type of training of the practitioner and the setting where he or she practices.

Included in the first group of TMPs were three general practitioners (sarvanga), three fracture healers, a snakebite healer, and specialists on paralysis, asthma, and kidney diseases (kidney stones). All these practitioners had their own private dispensaries and some of them came from well-known family traditions. Although they lie outside the official health care system, we felt it was still worthwhile to seek their views. The diploma holders (diploma in Ayurveda Sasthri) too practiced mainly in the private sector, although a few practitioners were attached to the government health care delivery system. All the degree holders (Bachelor of Ayurveda/Siddha Medicine and Surgery) in this sample were attached to the government Ayurveda health care delivery system. Some of them have also been involved with private practice only after duty hours in the government hospitals. Table 2 shows the distribution of practitioners based on the type of training and by gender. In Desiya Chikitsha the tradition is usually passed down to male members of the family, and women only get the opportunity to acquire it when there is no male heir. The predominance of males in our sample reflects the fact that the majority of such practitioners are male. Entry to the diploma and degree courses are by merit and women are more successful, hence they predominate in these fields of traditional medicine as they do in Western medicine.

In-depth interviews were conducted in April 2014 with each practitioner in order to obtain their views and their experience of primary health care within their everyday practice. ${ }^{12} \mathrm{~A}$ research assistant who came from a sociology/anthropology background conducted these interviews with practitioners in Sinhala by using an interview schedule under the supervision of a

\footnotetext{
12 We are very grateful to Sumudu Wijesooriya for translating the transcripts of the interviews from Sinhala into English.
} 
medical sociologist/anthropologist. The data was analyzed based on narratives of traditional practitioners. When quoting directly from the sample TMPs, they will be identified by an initial and a number in order to preserve their anonymity: TP refers to the family-trained practitioners, DP and DG to the diploma and degree holders respectively. Our sample of practitioners were asked a series of questions focusing on what they understood by the term "primary health care," whether they considered themselves to be involved in delivering it, their degree of collaboration with the government health sector, the level of cooperation with their colleagues in the Western medical sector, and whether they would like to be further integrated formally into the government primary health care system.

\section{How Did the Sample TM Ps Perceive Primary Health Care?}

A number of the practitioners explained in detail the connection between the concept of the three humors, the seven components of the body, and the five elements of the universe. Well-being, it was explained - and this encompassed mental well-being - is maintained by keeping a "harmonious balance" between the tridoshas of "wind, bile, and phlegm" (DP/7). When the humors are upset they become dosas, or troubles of the organism, and illness ensues. The most serious condition is the one in which all three humors are upset (sannipata). When a dosa is angry or excited, it increases in proportion to the other humors, so the aim of medication is to reduce or control this excess. The whole effort of Ayurveda, it was argued, was to enhance the healthy life of individuals while treating ill health when necessary to restore well-being. These explanations, given by all the TMPs, suggest that they were well aware of the idea of primary health care as preventive care, though their perspective had very different conceptual origins than that of the Western notion of PHC.

All the sampled practitioners emphasized that Ayurveda was concerned with the maintenance of good health but used the local term of suwastatava (well-being). The whole focus of the concept of suwastatava is to maintain the overall well-being of an individual (nirogikama) for a healthy life (nirogi jivitaya). Well-being depends on following a set of instructions for behavior from birth to death and for the individual's daily routine. These instructions encompass Ritu carya (seasonal routine), which includes coping strategies to adapt to seasonal variations, and Dina carya (daily routine), which covers personal hygiene, sleep patterns, food-related behavior, livelihood, and exercise. In addition there are strictures to ensure health during pregnancy and after childbirth. One TP described this routine as he lived it as follows: 
Almost all the things at our home are done according to the instructions of Ayurveda. They are planned according to these instructions from dawn to dusk. We get breakfast between 6 a.m. and 7 a.m. Bathing will be done before 12 noon.... All three main meals are cooked separately. We don't take cool foods. In addition, foods stored in a refrigerator are not consumed. (TP/3)

Seasonal behavior affected food patterns too:

In the summer season, hot foods such as tomatoes, pineapples, [and] pickles should not be eaten. It causes skin diseases, gastritis, and hemorrhoids. Similarly, cold foods eaten in the winter can cause phlegm. (DP/1)

Additionally, it was explained, there is a spiritual dimension to Ayurveda, and thus strategies for maintaining good relationships with others are deemed extremely important for both physical and mental well-being. In addition to maintaining well-being, Ayurveda has also developed some mechanisms for restoring the health of people who become ill for various reasons. Many of our TMPs argued that their treatments were safer than Western medical treatments because they were based on nature; examples of those holding this view can be found among all the TMP groups. "Our medicines don't cause side effects. But the Western system does," claimed one diploma holder (DP/o7). А тр from the first group went so far as to claim that "Western medicines are toxic. But, our medical system is natural. Therefore, it's not harmful for people" (TP/9). Ayurveda, argued yet another diploma holder, was "linked to nature" and "therefore, it is closer to human beings" (DP/5). The degree holders too supported the view that Ayurveda was based on nature: "NCDs [noncommunicable diseases, e.g., cardiovascular disease, diabetes, hypertension] can never be prevented without this natural health system," said one (DG/1). This argument about the naturalness of traditional remedies was based on the idea that locally grown herbs formed the mainstay of the compounds they prescribed. One тP commented that he "had grown many herbal plants at home" and that he gave them to patients and his family and used them himself (ТР/7). Another TP claimed that "our medicines are not imported though Western medicines are imported in limitless quantities" (TP/4). A DG argued that a TMP had "many roles. In treatments he is the doctor. When medicines are made he is the manufacturer. When he seeks herbal plants then he is the laborer." Yet others complained of the costs and difficulties of obtaining Ayurveda treatments; clearly they were referring to manufactured remedies (TP/9, DG/3, DP/7). In 1969 the government established the Ayurvedic Drugs Corporation, in order 
to act, according to its website, as "the pioneer of manufacturing and marketing of Ayurvedic drugs to the government hospitals, Ayurvedic physicians and the private sector" (Ayurvedic Drugs Corporation n.d.). Maarten Bode's (2008) recent analysis of how the commodification and commercialization of traditional medicines affects them casts some doubt on their "naturalness."

While the diploma and degree holders were aware of the Western concept of PHC, the practitioners of Desiya Chikitsha seemed not to be familiar with it. Two of the TPs mentioned vaccinations as being the only weapon in the armory of Western medicine's preventive arsenal (TP/2, TP $/ 5) \cdot{ }^{13}$ When the concept of PHC was explained to them, they laid claim to the appropriateness of Ayurveda for the objective of maintaining good health and preventing illness. As one TP succinctly put it: "There is no other medical tradition that explains primary health care as much as Ayurveda" (тР/6). Another concluded that "primary health care can be identified as living a balanced life without misbalancing the wind, bile, and phlegm levels" (тР/9). Although these practitioners do not consider themselves as contributing toward PHC in any formal sense, in reality they spend time with patients and their families explaining the means of maintaining a healthy life. Consultations involved giving instructions about lifestyle along the lines of the remarks quoted above. TPs emphasized too that it was important to establish a relationship with the patient. This attentiveness to the patient, as one TP argued, differentiated their approach from that of Western medical practitioners and made it more effective: "In the Western medical system, the doctor prescribes the medicine as soon as the patient is seen. We ask for details about the family and so on. Initially we try to construct a mental relationship with them because some illnesses are born in the mind" (тр/8). Thus at the grassroots level they argued that they clearly were propagating primary health care in its basic sense of prevention, through their emphasis on living a good and balanced life.

The interviews with the traditional practitioners who held a diploma or degree in Ayurveda revealed that they were more familiar with the term PHC than the practitioners of Desiya Chikithsa. These practitioners had obtained their qualifications either from the Institute of Indigenous Medicine (IIM) in Rajagiriya or from Wickramarchchi Ayurveda College in Gampaha, where they were taught PHC as part of the curriculum in the diploma/degree program. However, they rarely used the term "primary health care" in their everyday practice, as they used the local term suwastatawa for the same purpose. Like practitioners of Desiya Chikithsa, they too highlighted the importance of the concept of suwastatawa in Ayurveda when considering PHC. The

13 Four of the DPs also mentioned the importance of vaccination to the Western tradition. 
diploma holders in general and the degree holders in particular pointed out that Ayurveda has a much broader perspective on PHC than the Western notion of it: "Ayurveda discusses health care before primary health care. That is called primordial health care ... about prevention from conception. It extends beyond the Western medical tradition" (DG/3). They too emphasized the importance of the daily and seasonal routines and food patterns, and as the interviews made clear, one of the strongest justifications of the contribution that TMPs made or could make to primary health care was their work in the field of nutrition. Good nutrition is of course essential for both the capacity to fight off communicable diseases and the prevention of noncommunicable diseases. ${ }^{14}$

All categories of TMPs emphasized the importance of diet and food patterns in the maintenance of good health. As one TMP explained it, when asserting the superiority of traditional medicine in this regard:

Western medicine recommends that people eat five fruits and vegetables per day. These are mentioned in measureable quantities. But in our country people don't know what is called protein and minerals. Ayurveda describes six tastes. It recommends that people eat food with the six tastes. These tastes are: sweet, sour, salty, pungent, bitter, and astringent.... When we taste all six tastes, indirectly our body receives all the chemicals that we need. Our environment contains what we need for our wellbeing. It is closer to the people than asking them to eat five fruits and vegetables. (DG/1)

Another also highlighted the disconnection between Western medical advice on diet and the Sri Lankan natural environment: "Western practitioners explain the food pattern using a food chart but we explain beyond that. We consider the nature of the people" (DG/7). When working as a CMO this TMP "utilized the traditional knowledge of old people in the area to make young people aware of nutrition," and when involved with work on chronic kidney disease claimed that "we were very concerned about the foods they had in those areas. We taught them to use available foods as treatment for chronic kidney disease" (DG/7). With regard to child malnutrition, for instance, another argued cogently that

14 In June 2010, the First National Nutrition Policy was launched by the Health Minister, M. Sirisena; it was "formulated for the benefit of over $30 \%$ malnourished children in the country and the needy adult population" (Kannangara 2010). 
Prescribing vitamins to a rural mother with malnutrition is not an option. The solution should be found in the environment where a mother lives and this can avoid the vulnerability of child malnutrition. Unobtainable prescriptions are not the solutions to such problems. That's the point where the involvement of Ayurveda becomes essential because Ayurveda is linked with nature. (DP/9)

One of the TMPs who had worked as a Смо again showed the importance of a knowledge of local values in implementing nutrition programs. UNICEF, she noted, was providing milk to children with malnutrition when she was working as a См We taught them to prepare it in a way that would not provoke the phlegm" (DG/6). Clearly these cMOs could act as a bridge between the injunctions of the Western nutrition specialists and the local culture.

These critiques of the Western sector's advice on nutrition carry some weight. Certainly, for example, the food chart that accompanied a newspaper account of the launch of the National Nutrition Policy in 2010 contained food groups that look virtually identical to food charts in the Western world. The vegetables and fruits depicted were aubergine (eggplant), broccoli, carrots, grapes, and tomatoes; the proteins were chicken, fish, and cheese and the carbohydrates rice, beans, and bread (no jackfruit or coconut, for example, which are both nutritious and ubiquitous in Sri Lanka) (Kannangara 2010).

Primary health care in Ayurveda, the TM Ps argue, is not merely external to the individual but something that has been well integrated into normal living. The body constitution of each individual, they claimed, is unique and so Ayurveda has mechanisms that are integrated within the everyday life of the individual to maintain and improve well-being. Thus, the philosophy of Ayurveda guides an individual to organize both his or her personal life as well as social life in a healthy manner. The main focus of Ayurveda, they claimed, is not simply to treat the minority of ill individuals but to ensure a healthy and long life for the vast majority. All the traditional practitioners highlighted the importance of the broader perspective of Ayurveda on maintaining well-being, which goes beyond the western notion of PHC. Both Ayurveda and Buddhism contain within them the importance of the concept of equilibrium as part of a South Asian philosophical tradition that explores the whole process of achieving well-being through a middle path (Obeyesekera 1976). Thus, both Ayurveda and Buddhism encourage lay people to maintain a balance in their everyday life. All the TMPs incorporated these two philosophical traditions in their dayto-day practice. The following section explores the role of TMPs in the PHC 
delivery system against the objectives set for them in national and international policy pronouncements and documents.

\section{The Role of Traditional Medical Practitioners in the Formal Delivery of PHC}

The empirical evidence of this study revealed that the role of the TM Ps who belonged to the Desiya Chikithsa tradition in delivering PHC in any formal sense was nonexistent. They provided curative services for those seeking particular treatments related to their expertise, such as fractures, snakebites, and kidney stones. As a result, they were quite marginalized from the formal health care delivery system and had only a limited opportunity to be involved with individual or community health programs that are designed and implemented by the government healthcare delivery system, nongovernmental organizations (NGOs), and community-based organizations (своs). These practitioners have a very close relationship with their communities but they have little opportunity to collaborate with Western medical practitioners in PHC activities, and it is the Western practitioners who dominate the PHC delivery system at the grassroots level. However, in their answers the TMPs laid claim to a practice that uses their knowledge and skills to empower the patients who visited them by adopting user-friendly mechanisms; and although they offered specific curative services, they also gave advice in their consultations on living a healthy life. They could therefore be an extremely useful resource for offering advice on preventive health care that is connected with the cultural norms of their own communities.

Compared with the experience of practitioners of Desiya Chikithsa, the diploma/degree holders who were attached to the government Ayurveda health care delivery system had some space to get involved with formal PHC activities, though their contribution was limited to the patients who visited the Ayurveda hospitals. Eight of the diploma holders said that they had had no opportunity at all to work with Western practitioners in any respect. Two of them had had contact with the Western health care sector or more precisely with individuals working within it but on an informal basis. For example, one stated: "There are certain situations where patients are referred to us. But that referral is done just orally not formally. We also refer patients to western practitioners but only orally" (DP/5). Another said, "I am well accepted among the Western medical practitioners. I guess it's because of the reputation that our ancestral medical tradition has.... I have participated in clinics. Also the DMO [explain acronym] 
of the hospital refers heart patients to me. I also refer patients to the hospital. It all depends on the attitude of the Western practitioner" (DP/8). A third one noted that his local мон (explain acronym) had "taken Rathakalkaya from me as a child. Therefore he knows our methods. We don't receive any special support but we are not insulted. The Horana $\mathrm{MOH}$ works cooperatively with the Ayurveda doctors" (DP/9). ${ }^{15}$

However, all the diploma holders and 80 percent of degree holders mentioned that they had little opportunity to contribute to PHC when working within the hospital premises, as they had to focus their attention on the curative aspect rather than on prevention of diseases or health promotion. They highlighted the fact that there were no formal mechanisms to integrate them within the PHC delivery system.

Some insight can be gleaned from these interviews on how well the officially designated Ayurveda PHC CMO program established in 2004 operated, at least during the initial stages of the program. The study's sample of degree holders included four Ayurveda practitioners who had had experience as Ayurveda Community Medical Officers (cMOs). Though Ayurveda has its own institutional framework to deliver curative health care services in hospitals and clinics, there is no equivalent mechanism enabling Ayurveda practitioners to get involved with the PHC delivery system. Therefore, the cmos are attached to the Divisional Secretariat Office (DSO) and they are expected to work within the community as part of the Western government-sector PHC program. The experience of these cmos clearly suggested that the traditional practitioners could play a crucial role in PHC in the community. They had conducted various types of programs with the collaboration of Western medical practitioners at the community level in the areas of food and nutrition, especially in programs for preventing communicable and noncommunicable diseases; but their evidence also suggested that the level of cooperation depended very much again on personal relationships. One of the cmos pointed out that she had a pleasant experience as a Смо while she was working in Anuradhapura (in North Central Province, a predominantly rural area where the c мо program was first established). She described it thus:

While I was working at Anuradhapura, the мон wanted our contribution and I had a lot of support. I did my field visits in their vehicle. They treated me as a colleague. Our service was recognized. We organized a group for the Ayurveda First Aid program that included twenty students and two

15 Rathakalkaya is herbal water given to infants to improve their immunity. This was mentioned by several TMPs. 
teachers from each school in the area. They were trained for this purpose and we conducted a number of awareness raising programs, distributed leaflets, and so on. However, everything depends on the attitudes of the MOHs. If he or she is ready to appreciate our work we can do many things, but if not we fail. (DG/3)

The DG who had worked as a CMO in Bibila said she had spent all her time on primary health care and had worked on a project to eliminate malnutrition from the Monaragala district. Additionally, she had worked on the prevention of teenage pregnancy and conducted nutrition programs in schools. For example, as part of the nutrition program she gave instructions on how "to make food from batakirilla for the children with eczema. Also we promoted the use of buttermilk for the ones with digestive problems" (DG/6). ${ }^{16}$ She also had a good relationship with the local government health-sector workers. The "МоH and the midwives supported us a lot. We sat together and discussed the same topic from the two viewpoints" (DG/6).

Another DG had worked as a CMO in Ayagama and Yatiyanthota in Sabaragamuwa Province. She was one of the first appointments as a CMO. She commented that they had no facilities of their own but delivered lectures in мон clinics, Suwanaari (Well Woman Clinic), antenatal clinics, and vaccination clinics. ${ }^{17}$ "We were able to contribute to the areas where Western medicine has limitations," she said. "That is the reason they incorporate us into their programs, to fill those gaps" (DG/5). ${ }^{18}$

However, all these ex-CMOs were quite unhappy with the system within which they had been expected to work. For one thing, they had not been given even the basic minimum of infrastructural facilities to conduct their programs. One observed, for instance, that she had no facilities when she started- "not even a table or a chair" - but later an "NGO constructed an office for me" (DG/5). Another who had worked in Kurunegala commented that as a смо she was just working as an "individual with no staff" and had to "conduct clinics on her own to make the people aware of them. It's us who find the problems and the solutions too" (DG/7). She also highlighted the difficulties of getting

16 Batakirilla is a tree native to Sri Lanka whose leaves are traditionally used in Ayurveda for the treatment of dysentery and worm infestation.

17 Suwanaari are women's wellness clinics, run by the мон, that screen for cervical and breast cancer, high blood pressure, and so on.

18 She also stated that when she was introduced it was as the "indigenous мон." Since people were familiar with the role of the мон, this meant the audiences already had an understanding of the role of the смо. 
to places, as no transportation was officially provided nor, it seems, were they even given a fuel allowance. This lack of transportation was made more problematic for her by the fact that she "worked in an area where there are wild elephants" (DG/7). Another pointed out the difficulty of waiting "for buses holding laptops and projectors. It's impractical" (DG/6).

It seemed also that they had little autonomy in their work, as most of the programs at the grassroots level were organized by Western medical practitioners, and the cmos were expected merely to assist them. They therefore had little freedom themselves to design suitable programs within the community or to propagate their official services in the media, as their colleagues in the Western government sector were able to do. "We get opportunities to do that solely on the basis of personal connections" (DG/3). They pointed out that the MOH s verbally conveyed their appreciation of their services, but there was no formal mechanism to assess the contribution of cMOs when evaluating the outcome of those programs. So they were unhappy at the lack of equal recognition; the system did not allow them to work independently and they could only contribute in an ad hoc manner, despite the official nature of their appointments. As noted above, the level of cooperation depended almost totally on having a good personal relationship with the local мон. This empirical evidence suggested that the TMPs felt that their competency to contribute toward the PHC delivery system exceeded the bounds of what they were permitted to do, and that however much the government might pay lip service to the principle of using TMPs to deliver PHC and apportioning them an official role, appropriate mechanisms to ensure their full participation were not in place. For instance, one DG pointed out that there were year-long discussions before the National Nutrition Plan was declared in Monaragala in 2013, but the Ministry of Indigenous Medicine was not involved in those policy discussions. Only when this oversight was pointed out to the government was a letter sent out to Ayurveda nutrition specialists to ask for their contribution. "That's how they treat us" was this DG's judgment (DG/1). Tellingly, all the practitioners who contributed to this study mentioned that they had not been aware of the 20072016 master plan and claimed that they were seldom consulted by the government when preparing policies, even when they were supposedly integrally involved in them. While this lack of consultation might be expected in the case of the TPS, it is surprising that the DPs and DGs who worked in governmentfunded institutions had no notion either of their proposed official role. The following section explores the obstacles that according to our sample TMPs prevented the realization of the stated policy objective of integrating TMPS into the government health care system. 


\section{An Integrated Approach to PHC: Challenges}

The narratives of our sample TM Ps revealed that they felt that Ayurveda had a greater potential to contribute to P HC. They suggested that they clearly already had the required competency to contribute toward PHC and that they were willing to participate in an integrated approach. According to their views, each medical system has its own strengths and limitations and this attitude was evident across all three groups. Comments such as this one from a TP can serve to illustrate this: "It would be good if both traditions could get together, because they have the modern technological knowledge and we have treatments for many diseases like the chronic diseases" (TP/3). Integration would benefit patients because "when two traditions look at the same thing in two different ways, the patient can select the best for him" (DG/7).

Thus the traditional medical systems, practitioners claimed, had many strengths not only in addressing the root causes of disease but also in enhancing the well-being of people. On the other hand, the Western system had a very powerful mechanism for delivering PHC services at the grassroots level. Therefore, our sample TM Ps agreed that in theory an integrated approach with the collaboration of Western practitioners would be ideal for PHC.

However, most TMPs emphasized that the obstacles to integration primarily stemmed from the huge gap in status and capacity between the two systems. They pointed out that Western medical services received far more resources from the state. One director of an Ayurveda hospital illustrated the inadequate resources his hospital had to operate with:

We treat patients under the minimum facilities. We don't have gloves or at least cotton for our theaters. We have an X-ray machine but we don't have a qualified technician to work it. Even when we do provide health care awareness, we don't have any technical assistance. We have a limited staff so if we take a worker from the hospital to work in the programs the hospital schedule suffers. (DG/5)

Also, as one DP pointed out, much as she would have liked to contribute to PHC she did not have the time:

The Western practitioners are paid by the government; they can spend from 9 to 4 for such programs. I conduct a dispensary and I don't let any patient go back without meeting me. Many patients come in hired vehicles. I cannot ask them to come another day. (DP/3) 
The lack of resources given to Ayurveda stemmed from arguably the most significant obstacle, which was that Western practitioners perceived themselves as a group to be the superior professionals and thus dominated decision making as well as designing and implementing health programs. TM Ps from all the groups were very aware of this attitude and it presented real problems for them with regard to collaboration between the two sectors. As one TM P said, "We are willing to work collaboratively but the Western practitioners should change their negative attitudes toward us as well as to the traditional medical systems. At the same time we do need to be careful as it is difficult to transfer some of our concepts directly to the Western system" (DP/3). At the same time, there appeared to be little mutual understanding of what each other was doing at the grassroots level. The TMPs highlighted the fact that in the local context, most of the time the Western system operated against the traditional medical systems because of its practitioners' misconceptions with regard to traditional medicine. More than one TPM complained that Western practitioners castigated patients for consulting them, for example: "No opportunity has been offered to me to work with government officers. I don't think that they accept our methods. For example, they scold patients who have done oil massages when they visit the doctor" ( $\mathrm{TP} / 3)$. There were some Western medical practitioners who referred patients to indigenous practitioners. At the same time, however, others asked "Do you want to die?" when told that a patient wanted to visit an indigenous medical practitioner. This critical division, argued one DP, should be removed (DP/3).

Our sample TMPs also cited the banning of certain herbal medicines by the Western establishment as an example of their negative attitude toward traditional remedies, and argued that there was no rational basis for prohibiting remedies. These prohibitions were made without consulting TMPs or conducting laboratory investigations, and TMPs claimed that these remedies had been used for centuries with no side effects. The banning of the traditional practice of giving rathakalkaya - a traditional herbal medicine fed to infants to improve their immunity - had obviously proved to be a bone of contention for them. Thus, one DP commented, "International organizations have decided the things that should be done during pregnancy. Western medical practitioners have invaded primary health care.... The best thing we had in primary health care is rathakalkaya. The ones who used it are leading a good life still" (DP/9).

Rathakalkaya was banned on the grounds that some of the herbs used were toxic, but some TM Ps pointed out that no attempt was made to ascertain how the herbs were used to make up the infusion. Thus patients were discouraged from using time-honored herbal remedies for different ailments. As the TMPs 
emphasized, it was impossible to assess the qualities of a herbal plant by isolating it as an object. ${ }^{19}$ It was also pointed out by some TMPs that Western medicine too had side effects that, they argued, did not appear in official reports (DG/3).

The TMPs therefore highlighted the importance of taking the necessary action to change the attitudes of the Western medical practitioners, but they were clear that this should start at the policy making level. One remarked, "The policy makers should treat both of us equally. We should all be ready to serve our people without any differences. Ayurveda doctors should be given the same facilities to conduct research and both traditions should study each other" (DG/10). ${ }^{20}$ The evidence of our survey suggested that the PHC delivery system in Sri Lanka is highly dominated by the Western medical system, which is not yet ready to incorporate other knowledge systems. At present, except for recently created Ayurveda CMOs, all the other TMPs delivered their service in the formal sector only on the curative side, although they considered that they had indirectly been contributing toward the prevention of disease through the patients who visited them for treatment. The experience of our sample TMPS suggested that the Western practitioners did not have a favorable attitude toward the traditional medical systems and its practitioners; they believed that it had harmful effects on health and that the application of TMPs' remedies exacerbated ill health. Therefore, Western practitioners rarely referred their patients to TMPs, even when they themselves had no remedy, and even in cases where the traditional medical systems could claim some competency to solve the problem. This refusal to cooperate is all the more remarkable at a time when Ayurveda was establishing itself globally as a legitimate medical system and other so-called alternative systems, such as acupuncture and homeopathy, were likewise increasingly being utilized as therapies in the developed world for those conditions for which Western medicine seemed not to be effective. ${ }^{21}$ Similarly, even the ex-смоs in our sample claimed they had little opportunity to contribute in this regard, as there were no appropriate mechanisms in place to formally incorporate them into the national PHC delivery system. The ability to contribute to school and community health programs depended solely on their having a close relationship with the мон officers in the area. In this

19 For an exploration of the difficulties of transferring the biomedical approach to the assessment of alternative medicine, see Barry 2006; Waldram 2000; Bodeker 2001; Chaudhury 2001.

20 When research is done into Ayurvedic remedies it comes up with some interesting results. See, for example, Uragoda 1991; Perera 2005.

21 See, for example, Pole 2008; Chopra 2008. 
case integration with the Western system and its practitioners depended solely on the interests and behavior of the individual Western medical practitioner in the area.

Our sample TPS were aware that the government was slowly starting to recognize their capacity to deal with contemporary health problems and that the Смо initiative was the result of this recognition, although they were not aware of the Health Master Plan 2007-2016. ${ }^{22}$ They did think that the government should be developing appropriate mechanisms to formally integrate the traditional medical systems with the Western medical system, but so far there were no signs of this happening; crucially, for instance there was no formal referral system whereby patients could be referred from one system to the other according to what might be appropriate. Such a referral system would be both a marker of formal equality and a mechanism to deliver the benefits of traditional medicine at the grassroots level. The TMPs also argued that an effective mechanism to distinguish what they termed "quacks" from proper TMPs was vital, as its lack had obvious negative consequences for the traditional medical systems.

\section{Conclusion}

The paper attempted to explore how TMPs perceived PHC and whether they saw themselves as an integral part of the health sector with an essential part to play in delivering it. The traditional practitioners in our sample had their own language to explain the concept of PHC and they perceived it as something similar to the concept of suwastatawa in Ayurveda. They argued that traditional medicine had a greater capacity to contribute to PHC, in that it was more far-reaching than the Western system. However, they did not feel that they had been actively involved with the PHC delivery system to date, as they had encountered few opportunities in this regard. Although the 2007-2016 Health Master Plan certainly laid down that TMPs should be fully involved in PHC, there were no proper mechanisms to formally incorporate them within PHC delivery activities. However, the TMPs considered that they contributed indirectly to PHC in their personal capacity as healers. In rural areas, most of the Government mos who delivered different services at the community level have a structure for implementing various types of interventions, and some

22 By 2009 there were 325 CMOs deployed across the island to implement disease prevention programs. We are unable to comment on whether they are now better integrated than our sample смоs claimed to be. 
TMPs in our sample too were involved these activities. They strongly believed that patients would receive more benefits if traditional and modern systems could collaborate with each other in service delivery. The TMPs also believed that they too would benefit from this, as they would be recognized as equals and thus have more opportunities to contribute their knowledge and skills as well as the resources to do so. The findings suggest that the CMOs in particular could play a more crucial role in this regard. However, in general there were no effective mechanisms to incorporate TMPs into the health care delivery system formally, nor did TM Ps possess the necessary facilities and power to design and implement programs within the community.

The findings clearly show that there has been a huge gap in implementing the Health Master Plan 2007-2016, and appropriate strategies to make it a reality are still required at a primary level. Basically, there are two challenges, one at the policy level and the other at the practical level. Theoretically, the traditional medical systems have a greater capacity to contribute toward PHC, especially in relation to lifestyle choices and the prevention of NCDs. However, it appears that the difficulties may be insurmountable because of the hierarchy between traditional and modern systems of health care: the dominant system-Western medicine- has the overall advantage in funding and status and the traditional medical systems become substandard. Policies are required to reduce the gap between the two systems. Western medical practitioners have been hostile to the traditional system since traditional practitioners first moved to obtain official recognition and funding in the 1920s, and our study revealed that this prejudice may still present a huge barrier that prevents them from working with their TMP colleagues. Furthermore, there is a requirement to implement strategies to remove the misconceptions that both systems hold about each other. Although there are some courses at the Ayurveda College to provide students with a basic knowledge of the Western medical system, similar courses are not taught at the Western medical colleges to equip those training as Western medical practitioners with a basic knowledge of Ayurveda, although presumably many will have some experiential knowledge of it. In conclusion, the traditional medical systems have the capacity to contribute toward PHC and their practitioners are willing to contribute. However, the government has not succeeded in developing appropriate mechanisms to integrate the TMPs into the country's PHC delivery system in order to implement the Health Master Plan 2007-2016. Our survey suggested that this stems from the historical hierarchical divide between the two medical systems on the island, where Western medicine receives the major share of government resources and therefore the greater capacity to influence the implementation of policies both at the national and the local level. 


\section{References}

Arseculeratne, S.N. 2002. "Interactions between Traditional Medicine and 'Western' Medicine in Sri Lanka." Social Scientist 30 (5): 4-17.

Ayurvedic Drugs Corporation. N.d. “Overview." Sri Lanka Ayurvedic Drugs Corporation. www.ayrvediccorp.gov.lk (accessed March 14, 2013.

Banerjee, Madhulika. 2008. "Ayurveda in Modern India: Standardization and Pharmaceutilization." In Modern and Global Ayurveda: Pluralism and Paradigms, edited by Dagmar Wujastyk and Frederick M. Smith, 201-214. Albany: State University of New York Press.

Barry, Christine Ann. 2006. "The role of evidence in alternative medicine: Contrasting biomedical and anthropological approaches." Social Science and Medicine 62: 26462657. doi:10.1016/j.socscimed.2005.11.025.

Bode, Maarten. 2008. Taking Traditional Knowledge to the Market: The Modern Image of the Ayurvedic and Unanic Industry, 1980-200o. Himayatnagar, India: Orient Black Swan.

Bodeker, Gerard. 2001. "Lessons on Integration from the Developing World's Experience." British Medical Journal 322 (7279): 164-167.

Caldwell, J., I. Gajanayake, P. Caldwell, and I. Peiris. 1989. "Sensitization to illness and the risk of death: an explanation for Sri Lanka's approach to good health for all." Social Science and Medicine 28 (4): 365-379.

Chan, Margaret. 2008. "Return to Alma Ata." Lancet 372 (September 13): 865-866.

Chaudhury, Ranjit Roy. 2001. "Commentary: Challenges in using traditional systems of medicine." British Medical Journal 322 (7279): 167.

Chopra, Ananda Samir. 2008. "Practicing Ayurveda in the Western World: A Case Study from Germany." In Modern and Global Ayurveda: Pluralism and Paradigms, edited by Dagmar Wujastyk and Frederick M. Smith, 243-256. Albany: State University of New York Press.

Cueto, Marcos. 2004. "The Origins of Primary Health Care and Selective Primary Health Care." American Journal of Public Health 94 (11): 1864-1875.

De Silva, K.M. 1997. "Introduction." In Sri Lanka: Part I, The Second World War and the Soulbury Commission, 1939-1945. British Documents on the End of Empire, edited by K.M. De Silva, vii-cvi. London: HMso.

Department of Ayurveda. N.d. Desiya Chikithsa. Department of Ayurveda, Ministry of Health, Nutrition and Indigenous Medicine. www.ayurveda.gov.lk.medicine/ ayurveda.html (accessed March 14, 2013).

Dunn, Fred. 1976. "Traditional Asian Medicine and Cosmopolitan Medicine as Adaptive Systems." In Asian Medical Systems: A Comparative Study, edited by Charles Leslie, 133-158. Berkeley: University of California Press.

Fernando, Dulitha. 2000. "An overview of Sri Lanka's health care system." Journal of Public Health Medicine 22 (1): 14-20. 
Fernando, Malinga, and Tissa Cooray. 1991. "Sri Lanka: deep roots in primary health care." In Achieving Health for All, edited by E. Tarimo and A. Creese, 229-243. Geneva: wHO. www.wholibdoc.who.int/publications/1991/924561327_srilanka.pdf (accessed October 25, 2012).

Halstead, S., J.A. Walsh, and K.S. Warren, eds. 1985. Good Health at Low Cost. Bellagio: Rockefeller Foundation.

Hewa, Soma. 1995. Colonialism, Tropical Disease and Imperial Medicine: Rockefeller Philanthropy in Sri Lanka. Lanham, MD: University Press of America, 1995.

Jones, Margaret. 2004. Health Policy in Britain's Model Colony: Ceylon (1900-1948). Hyderabad: Orient Longman.

Jones, Margaret. 2008. "A Bounded Medical Pluralism: Ayurveda and Western Medicine in Colonial and Independent Sri Lanka." In The Development of Modern Medicine in Non-Western Countries: Historical Perspectives, edited by H. Ebrahimnejad, 108-126. London: Routledge.

Jones, Margaret. 2009. The Hospital System and Health Care: Sri Lanka, 1815-1960. Hyderabad: Orient BlackSwan.

Kannangara, Ananada. 2010. "A boost for malnourished schoolchildren." Sunday Observer, June 27. www.sundayobserver.lk/2010/06/27/junı.asp (accessed June 7, 2014).

Lawn, J.E., S. Rifkins, M. Were, K.P. Vinod, and M. Chopra. 2008. "Alma-Ata: Rebirth and Revision 1. Alma-Ata 30 years on: revolutionary, relevant, and time to revitalize." Lancet 372 (September 13): 917-926.

Lewis, Milton, and Kerrie MacPherson. 2013. Health Transitions and the Double Disease Burden in Asia and the Pacific. London: Routledge.

Mahler, Halfdan. 1978. "Promotion of Primary Health Care in Member Countries of WHO." wHo Congress on Traditional Medicine. Public Health Reports, International Health 93 (2): 107-113.

Ministry of Health (Sri Lanka). N.d. "Community Healthcare Services through Ayurveda." Development Programme of the Ministry. http://www.indigenous medimini.gov.lk/Development_Program.html (accessed March 14, 2013).

Ministry of Health (Sri Lanka). 2003. Annual Health Bulletin, 2003. Colombo: Ministry of Health. www.health.gov.lk (accessed January 18, 2013).

Ministry of Health (Sri Lanka). 2017. "Introduction, 1.1.1, Overview of current health status." National Health Development Plan, Ministry of Health Sri Lanka, 4. www.health .gov.lk/enWeb/publication/NHDP2013-2017-page1-10opdf (accessed February 2, 2017). Ministry of Healthcare and Nutrition (Sri Lanka). 2007. Health Master Plan 2007-2016: Healthy and Shining Island in the 21st Century. Colombo: Ministry of Healthcare and Nutrition.

Obeyesekera, Gannath. 1976. "The Impact of Ayurvedic Ideas on the Culture and the Individual in Sri Lanka." In Asian Medical Systems: A Comparative Study, edited by Charles Leslie, 201-227. Berkeley: University of California Press. 
Perera, Antoinette. 2005. "Use of plants in primary medical care-beliefs, practices and research." College Oration 26:1, 19-23. Colombo: College of Family Physicians.

Pieris, Indrani. 1999. Disease, Treatment and Health Behaviour in Sri Lanka. New Delhi: Oxford University Press.

Pole, Sebastian. 2008. "Practicing in the United Kingdom: A Time of Challenges and Opportunities." In Modern and Global Ayurveda: Pluralism and Paradigms, edited by Dagmar Wujastyk and Frederick M. Smith, 215-226. Albany: State University of New York Press.

Simeonov, L.A. 1975. Better Health for Sri Lanka: A Report on a Health Manpower Study. World Health Organization, Regional Office for South East Asia, New Delhi, sEA/ PHA/149. Geneva: WHO.

Uragoda, C.G. 1991. "A Scientific Basis for some Traditional Beliefs and Practices in Sri Lanka." Journal of the Royal Asiatic Society of Sri Lanka, n.s., 34: 1-13.

Waldram, James B. 2000. "The Efficacy of Traditional Medicine: Current Theoretical and Methodological Issues." Medical Anthropology Quarterly, n.s., 14 (4): 603-625.

Wanninayaka, P.B. 1982. Ayurveda in Sri Lanka. Colombo: Ministry of Health.

wHo (World Health Organization). 1978a. "Declaration of Alma-Ata, International Conference on Primary Health Care, Alma-Ata, USSR, 6-12 September 1978." www .who.int./hpr/NPH/docs/declaration_almaata.pdf (accessed October 15, 2012).

wHO (World Health Organization). 1978b. "The promotion and development of traditional medicine." World Health Organisation. Technical Report Series 622. who.int/ iris/handle/10665/40995 (accessed February 24, 2014).

wHo (World Health Organization). 2008a. The Beijing Declaration. wHo Congress on Traditional Medicine, September 7-9, 2008, Beijing. www.who.int/medicines/ areas/traditional/congress/en (accessed February 19, 2014).

wHo (World Health Organization). 2008b. Primary Health Care-Now more than ever. World Health Report 2008. www.who.int/whr/2008/whro8_en.pdf (accessed February 20, 2014).

Wujastyk, Dagmar, and Frederick M. Smith. 2008. "Introduction." In Modern and Global Ayurveda: Pluralism and Paradigms, edited by Dagmar Wujastyk and Frederick M. Smith, 1-28. Albany: State University of New York Press.

Young, Allan. 1983. "The Relevance of Traditional Medical Cultures to Modern Primary Health Care." Social Science and Medicine 17 (16): 1205-1211. 